\title{
Stridor in Epiglottic Cyst: A Rare Presentation
}

S Chandrakala, Nikhil S Bhardwaj, Kouser Mohammadi, Lakshmi Menon

\section{ABSTRACT}

Objective: To emphasize that epiglottic cyst should be considered in the differential diagnosis of all adults presenting with stridor.

Case report: A 55-year-old male patient presented with stridor of 2 days duration. He also had complaints of gradually progressive difficulty in swallowing for solids and had muffled voice for the past 3 months. Oropharyngeal examination revealed a large cystic mass behind the base of tongue. An indirect laryngoscopy and $70^{\circ}$ telescopic laryngoscopy showed a large cystic mass filling both vallecular regions obscuring rest of the larynx. He underwent tracheostomy for airway distress followed by excision of the cyst.

Conclusion: This case highlights the possibility of a rare presentation of epiglottic cyst in an adult presenting with stridor requiring an early definitive management.

Keywords: Epiglottic cyst, Stridor, Tracheostomy, Exicision.

How to cite this article: Chandrakala S, Bhardwaj NS, Mohammadi K, Menon L. Stridor in Epiglottic Cyst: A Rare Presentation. Int J Head Neck Surg 2013;4(2):110-111.

Source of support: Nil

Conflict of interest: None declared

\section{INTRODUCTION}

Epiglottic cyst is a rare entity, presentation with stridor is still rarer. They are mostly asymptomatic, but if large enough can compromise the airway and present with stridor. Here we highlight a rare case of large epiglottic cyst presenting with stridor. It is emphasized that epiglottic cyst should be considered in the differential diagnosis of adults presenting with stridor.

\section{CASE REPORT}

A 55-year-old man with history of muffled voice and difficulty in swallowing for solids of 3 months presented to otorhinolaryngology department with stridorous breathing of 2 days duration. Oro pharyngeal examination revealed a large cystic mass behind the base of tongue. Indirect laryngoscopy and telescopic examination of larynx showed a large cystic mass filling both the vallecula, but its origin could not be identified (Fig. 1). As cyst was pushing epiglottis to posterior pharyngeal wall rest of endolarynx was not visualized. Radiograph of the neck revealed a large cyst at the level of $\mathrm{C} 2$ to $\mathrm{C} 4$ (Fig. 2).

He was taken up for emergency surgery in view of impending airway compromise. Tracheostomy was done anticipating difficult intubation. Boyle Davis mouth gag was placed; a cyst measuring about $4 \mathrm{~cm}$ in diameter was visualized in the vallecular region. A thick cheesy material was aspirated from cyst to reduce its size, after which it was seen arising from right half of the lingual surface of epiglottis. Cyst was excised in toto and the base was cauterized. Recovery was uneventful and he was decanulated after 2 days. A well healed surgical wound was seen at the end of the 7th postoperative day (Fig. 3).

\section{DISCUSSION}

Laryngeal cyst is a benign tumor and constitutes 4.3 to $6 \%$ of all benign laryngeal tumors. ${ }^{1} 52 \%$ of the laryngeal cysts originate from lingual surface of the epiglottis. ${ }^{2}$ They may be congenital or acquired. Congenital epiglottic cyst always causes respiratory distress or even sudden death. ${ }^{3}$ Early

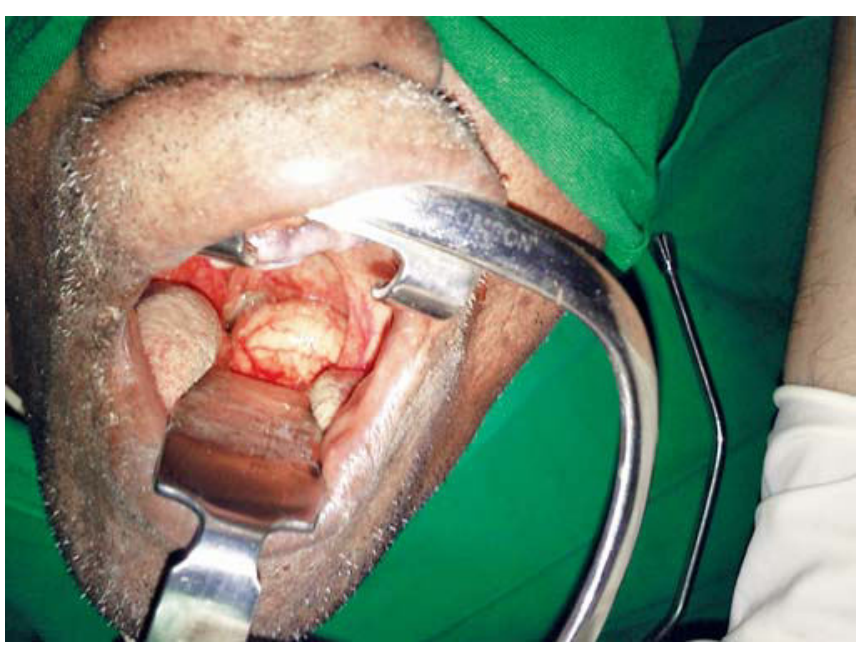

Fig. 1: Epiglottic cyst extending to oropharynx

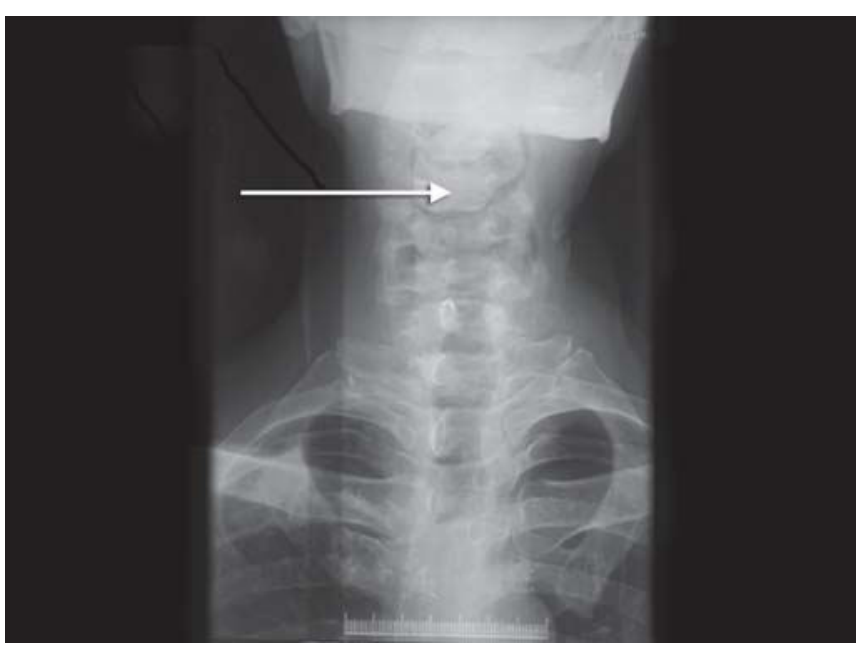

Fig. 2: Radiograph of neck showing a large cyst compressing the airway at the level of $\mathrm{C} 2$ to $\mathrm{C} 4$ 


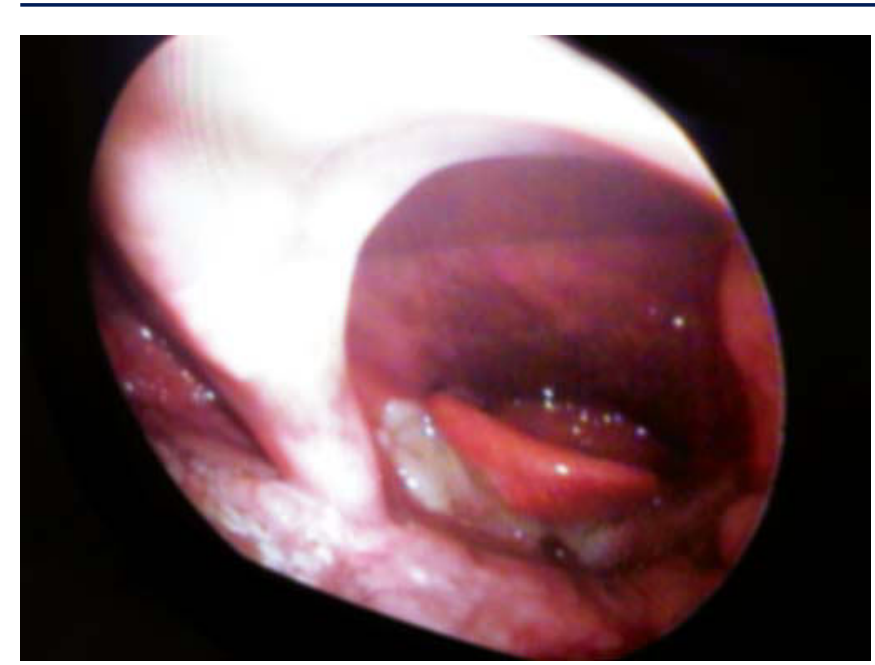

Fig. 3: 7th day Postop view of vallecula and epiglottis

identification and timely intervention is life saving in these cases.

Epiglottic cysts are incidental findings in adults. Most of the adult epiglottic cysts are detected at 6 th decade. ${ }^{1}$ Presentation in adult may vary from asymptomatic (small cyst) and mild dysphagia to complete airway obstruction. Secondary infection in the cyst can occur causing acute epiglottitis and epiglottic abscess leading to sudden airway obstruction. $^{2}$

There are various pathological classification of laryngeal cysts. DC Santo classified them into ductal, saccular and thyroid cartilage foraminal types. Ductal (mucus retention) cysts are thought to originate from obstructed submucosal or salivary glands. Saccular cysts are less common and occur in the plane of saccule. The modified working classification divides cysts into epithelial, tonsillar and oncocytic. A pathological classification by Ying Li Yun divides cyst into retention, branchial cleft and epidermoid cysts.

The treatment of choice for large epiglottic cyst is surgical excision. Large cyst causing airway obstruction is an indication for tracheotomy prior to excision. ${ }^{2}$ Intubation is difficult in such cases because it's difficult to place the tip of the laryngoscope into vallecula and lift the epiglottis. ${ }^{3}$ There are reports of death during intubation of large cysts. ${ }^{4,5}$

Various surgical methods include excision using nasal endoscopes and Laser, microscope and $\mathrm{CO}_{2}$ Laser, Side opened laryngoscope with snare and microdebrider. ${ }^{6-8}$

In our case, the patient presented with stridor, dysphagia and muffled voice. The cyst was large enough to be visible behind the base of tongue at oropharyngeal examination using a tongue depressor. After basic hematological and radiological investigation, patient was planned for surgery.
Tracheotomy was performed. The cyst was exposed using Boyle-Davis mouth gag and excised in toto. A $3.5 \mathrm{~cm}$ cyst has been reported by Fang in 2007. The size of cyst was $4 \mathrm{~cm}$ in this patient, which is one of the largest, reported in literature till date.

\section{CONCLUSION}

Large epiglottic cyst can present as airway obstruction. This case highlights the possibility of a rare presentation of an adult epiglottic cyst with stridor and difficulty in breathing requiring an early definitive management.

\section{REFERENCES}

1. Lam HCK, Abdullah VJ, Sod G. Epiglottic cyst. Otolaryngol Head Neck Surg 2000;112:311.

2. Henderson LT, Denny JC, Teichgraeber J. Airway obstructing epiglottic cyst. Ann Otol Rhinol Laryngol 1989;94:473-76.

3. Lee WS, Tsai CSS, Lin CH, Lee CC, Hsu HT. Airway obstruction caused by a congenital epiglottic cyst. Int $\mathrm{J}$ ped Otorhinolaryngol 2000;53:229-33.

4. Padfield A. Epiglottic cysts: A case report and review. Anaesthesia 1972 Jan;27:84-88.

5. Jorgenson BK. Epiglottic cysts as a cause of anesthetic death. Ugeskr Larger 1974;136:1743-44.

6. Shenoy P, Malik SA, AlDuwillah R. A New Approach for the Treatment of Large Epiglottic Cysts using Nasoendoscopes. Kuwait Medical Journal 2007;39(1):59-61.

7. Su CY, Hsu JL. Transoral laser marsupialization of epiglottic cysts. Laryngoscope 2007 Jul;117(7):1153-54.

8. Kawaida M, Kohno N, Kawasaki Y, et al. Surgical treatment of large epiglottic cysts with side-opened direct laryngoscope and snare. Auris Nasus Larynx 1992;19:45-50.

\section{ABOUT THE AUTHORS}

\section{S Chandrakala (Corresponding Author)}

Assistant Professor, Department of Otolaryngology and Head and Neck Surgery, Sri Devaraj URS Medical College, Kolar, Karnataka India, e-mail: chanduharish24@yahoo.com

\section{Nikhil S Bhardwaj}

Assistant Professor, Department of Otolaryngology and Head and Neck Surgery, Sri Devaraj URS Medical College, Kolar Karnataka, India

\section{Kouser Mohammadi}

Junior Resident, Department of Otolaryngology and Head and Neck Surgery, Sri Devaraj URS Medical College, Kolar, Karnataka, India

\section{Lakshmi Menon}

Junior Resident, Department of Otolaryngology and Head and Neck Surgery, Sri Devaraj URS Medical College, Kolar, Karnataka, India 